\title{
REFLEXÕES SOBRE O PAPEL DOS PARTIDOS NO SISTEMA POLÍTICO BRASILEIRO: ATIVIDADE PARLAMENTAR EM CONTEXTO DE PREPONDERÂNCIA DO EXECUTIVO
}

\author{
Reflections on the role of parties in the Brazilian political system: parliamentary \\ activity in context of preponderance of the executive
}

Vinicius Silva ALVES

Doutor em Ciência Política pela Universidade de Brasília. vinicius.silvalves@gmail.com http://orcid.org/0000-0001-7880-0022

Mais informações da obra no final do artigo

\section{RESUMO}

O presente trabalho oferece uma reflexão sobre as possibilidades de atuação de deputados federais no sistema político brasileiro, marcado pela preponderância do Poder Executivo. Admite-se que a preocupação com a continuidade de suas carreiras políticas condiciona o comportamento e atuação dos parlamentares. O texto apresenta, após uma breve introdução, que ilustra as bases sobre as quais se desenvolvem as relações entre Executivo e Legislativo no Brasil, a literatura que nos auxilia a compreender as decisões que os atores políticos tomam ao longo de suas carreiras. Em seguida, são discutidas as interpretações e achados sobre a atuação dos deputados brasileiros, assim como as críticas que podem nos ajudar a compreender a atividade parlamentar sob uma perspectiva mais dinâmica. Ao final, sugerimos que os partidos políticos condicionariam as possibilidades de atuação de seus membros, oferecendo vantagens e obstáculos às atividades dos aliados e dos oposicionistas em relação ao governo federal.

PALAVRAS-CHAVE: Partidos políticos. Relação Executivo-Legislativo. Atividade parlamentar.

\begin{abstract}
This paper offers a discussion on the possibilities of action of federal deputies in the Brazilian political system, marked by the preponderance of the Executive branch. It is argued that the continuity of their political careers may constrain the congressmen behavior. After a brief introduction that illustrates the bases on which the relations between Executive and Legislative are developed in Brazil, we present the literature that helps us to understand the decisions that the political actors take during their careers. Next, we discuss the many findings on the Brazilian deputies performance, as well as the criticisms that may help us to understand parliamentary activity from a more dynamic perspective. In the end, we suggest that political parties might constrain the possibilities of action of their members, offering advantages and obstacles to the activities of allies and oppositionists towards the federal government.

KEYWORDS: Political parties. Executive-Legislative relations. Congressmen activities.
\end{abstract}




\section{INTRODUÇÃO}

A sedimentação de experiências democráticas frustradas, interrompidas após turbulências decorrentes de instabilidades nas relações entre o gabinete e o parlamento, fez com que se enaltecesse a importância do fortalecimento institucional do chefe do Executivo no Brasil (MELO \& PEREIRA, 2013). A ameaça latente à ordem democrática, caracterizada pela inexistência de instituições eficientemente delineadas para processar e solucionar, por intermédio das vias sistêmicas, os impasses institucionais, - como ocorreu com a paralisia decisória que antecedeu o Golpe Militar de 1964 (SANTOS, 1986) - exigiu daqueles que se debruçaram sobre o tema relevantes esforços e considerações. $O$ processo de transição democrática, acentuado a partir da segunda metade da década de 1980, não perdeu de vista esta questão, mormente ao considerarmos o caráter quase intermitente da alternância entre regimes de cunho democrático e autoritários na história recente brasileira.

Em meio a este cenário de nova retomada de uma ordem política incompatível com o autoritarismo, a promulgação da Constituição da República de 1988 almejou equilibrar a relação entre os mencionados poderes, com vistas à edificação e manutenção de um sistema político democrático, sendo parte integrante do processo de transição política iniciado no fim dos anos setenta. O texto constitucional vigente, por conseguinte, distribuiu, de maneira generosa, recursos institucionais ao chefe do Executivo, visando promover um ambiente que favorecesse a estabilidade democrática (MELO \& PEREIRA, 2013). Minimizaram-se, dessa maneira, as forças centrífugas do sistema político brasileiro, permitindo-se o processamento das disputas e instabilidades políticas pelas vias institucionais, o que contribuiu para se evitar a ameaça de democratic breakdowns (MARSTEINTREDET, 2014).

O papel do presidente da República como protagonista do processo legislativo e orçamentário (FIGUEIREDO \& LIMONGI, 1999; PESSANHA, 2002), além de sua participação marcante na definição de agentes públicos que ocupam cargos em instituições fiscalizadoras podem ser considerados reflexos que se notam a partir da vigente disciplina constitucional. Com efeito, é possível observar que o design institucional das Casas Legislativas situadas no plano federal, em especial o da Câmara dos Deputados, favorece o protagonismo do chefe do Executivo na condução dos processos políticos destinados à tomada de decisões substantivas e relevantes à comunidade política (FIGUEIREDO \& LIMONGI, 1999). Destaca-se, ainda, que, ao contrário das 
predições elaboradas por estudiosos do final da década de 1980 e da década seguinte (ABRANCHES, 1988; LINZ, 1993; MAINWARING, 1999), a combinação de elementos como representação proporcional, sistema multipartidário e presidencialismo não se revelou um obstáculo à manutenção do arranjo institucional democrático idealizado pelos constituintes (MELO \& PEREIRA, 2013).

Não mais se observam predições catastróficas sobre o destino da democracia brasileira, que tem dado importantes demonstrações de que é possível a solução de conflitos políticos pelas vias institucionais (MARSTEINTREDET, 2014). Todavia, não há consenso entre os pesquisadores que se dedicam ao tema sobre a necessidade e conteúdo de reformas políticas (RENNÓ, 2006), o que sinaliza a importância do debate sobre alguns pontos tidos como centrais na avaliação do sistema brasileiro.

Destaca-se, nesse momento, que as ambições por normalidade democrática não podem perder de vista a relevância da competitividade para a qualidade de um regime político, especialmente ao considerarmos que o arrefecimento da concorrência nos pleitos eleitorais pode sugerir um retrocesso no eixo da contestação pública (DAHL, 2005).

O presente trabalho orienta-se, então, a partir da dúvida sobre um dos elementos que Melo e Pereira (2013) afirmam conferir estabilidade ao sistema político brasileiro. De acordo com os autores, o inesperado sucesso da democracia no Brasil pode ser explicado pela existência de um presidente constitucionalmente forte, de mecanismos que favorecem barganhas institucionais e a cooperação entre os poderes Legislativo e Executivo, além da manutenção de mecanismos autônomos de accountability horizontal.

O ponto que serve de inspiração para o desenvolvimento deste trabalho é, especialmente, a dúvida em relação à viabilidade da atuação independente das instituições parlamentares de fiscalização e controle. Argumenta-se que, a depender da extensão da influência da associação entre o presidente da República e os deputados federais, mediada pelos partidos políticos, na reeleição destes parlamentares, pode-se estar diante de um panorama no qual a luta competitiva por cargos na Câmara Baixa esteja comprometida.

Isto porque as chances de reeleição de um deputado integrante de um partido da coalizão poderiam ser incrementadas em certo nível, quando comparadas com os que concorrem à reeleição por um partido excluído do gabinete, que tal situação sugeriria que o alinhamento aos projetos governistas pudesse ser um elemento que proporciona desequilíbrio de recursos e oportunidades favoráveis à continuidade das carreiras de deputados federais. 
Sobre o tema, vale salientar que a estrutura institucional que disciplina o jogo político-eleitoral, notadamente $\mathrm{o}$ arranjo constitucional, desempenha papel influente no nível de corrupção política de um regime. Neste sentido, os achados de Kunicová e RoseAckerman (2005) sugerem que a combinação entre representação proporcional e presidencialismo podem expor um sistema político a ameaças latentes de corrupção, como se observa da leitura do trecho a seguir transcrito:

Under PR, coalitions are common, and in many countries parties do not sort themselves into two stable blocs. Instead, a party currently in opposition may expect to form a coalition with one or more of the incumbent parties sometime in the future. If this is so, opposition politicians may want to form a coalition with a party currently in power. If so, they have little incentive to expose the corruption of politicians whom they might need to collaborate with in the future (...)This could produce a race in which opposition parties compete to reveal a scandal, but under plausible conditions, everyone may keep quiet if the cost of uncovering malfeasance is high and/or if the scandalmonger is punished by being excluded from future coalitions. (KUNICOVÁ \& ROSE-ACKERMAN, 2005, p. 584)

As inferências trazidas pelas autoras revelam-se úteis para a interpretação e exame de sistemas políticos democráticos que mesclam presidencialismo e representação proporcional ao multipartidarismo, como o caso brasileiro. Tal assertiva se justifica, especialmente, pela observação do posicionamento estratégico dos partidos políticos, que procuram usufruir das vantagens institucionais decorrentes da associação com o partido que ocupa a chefia do Executivo, como, por exemplo, o recebimento de uma pasta ministerial (LAMEIRÃO, 2009), o qual permite acesso facilitado a recursos financeiros destinados a seus nichos eleitorais, elemento que pode se transformar em vantagem competitiva para a sobrevivência política dos aliados.

Muito embora se reconheça o cuidado que se faz necessário na aplicação do modelo distributivista para a interpretação do sistema político nacional, segundo o qual os deputados utilizam-se do pork barrel para manutenção de seus mandatos (SANCHES FILHO \& CARVALHO, 2012), justifica-se um exame das estratégias de sobrevivência política de deputados aliados em perspectiva comparada com aqueles que se opõem ao governo, sobretudo em virtude dos efeitos que estas estratégias podem ter sobre as chances de reeleição dos deputados integrantes de partidos da coalizão, o que poderia ter implicações sobre a eficácia dos mecanismos de fiscalização e controle do governo trazidos pela constituição vigente.

Sobre os riscos da manutenção de um sistema político que oferece obstáculos à atuação independente dos mecanismos de fiscalização e controle dos agentes públicos, 
observa-se que "[...] the impact of competitive politics on the monitoring of corrupt rentseekers may actually fall as the number of parties increases. The number of parties is a poor proxy for the intensity of competition, at least with respect to the control of corrupt self-enrichment by politicians." (KUNICOVÁ \& ROSE-ACKERMAN, 2005, p. 584).

Nessa ordem de ideias, a despeito das consideráveis taxas de renovação parlamentar apontadas por Samuels (2003), bem como tendo em vista as restrições trazidas por Sanches Filho e Carvalho (2012) sobre a utilização do modelo distributivista como instrumento de análise do sistema brasileiro, é preciso que se considere que os recursos de poder, tais como o acesso a comissões que instrumentalizam a accountability horizontal, em geral, pode estar sendo franqueado a deputados com maior experiência, conhecedores das vantagens competitivas que a inclusão de seu partido na coalizão pode Ihes render.

Cabe lembrar, nesse momento, que a atuação dos congressistas pode ser compreendida por intermédio do conhecimento de seus objetivos e anseios. Salienta-se que a premissa de que todo parlamentar tem por objetivo sua reeleição, inspirada nas obras de Schumpeter (1961) e Downs (1999), guia os estudos sobre comportamento legislativo e serve de esteio para a condução deste trabalho. De acordo com Melo (2003, p. 188), afirma-se que:

Ao deputado, interessa situar-se em posição que possibilite um bom desempenho na execução de uma estratégia voltada para a transferência de recursos públicos para sua base eleitoral, - ainda que ele possa saber que este não é o fator determinante para seu sucesso e que exista todo um trabalho para transformar, por exemplo, uma emenda orçamentária em crédito aos olhos do eleitorado. E o sucesso desta empreitada (ou pelo menos da etapa correspondente à aprovação e execução de uma emenda proposta) pode depender do partido em que esteja o deputado.

Muito embora haja certas peculiaridades no enfrentamento de algumas questões, a literatura sobre o tema (FENNO, 1973; MAYHEW, 2005; ARNOLD, 1990; ALDRICH, 1995) converge para o entendimento de que, embora os parlamentares não se orientem apenas pela manutenção de suas cadeiras nas Casas Legislativas, esta preocupação condiciona o seu comportamento e atuação. Assim, após o início da reflexão sobre os fatores que auxiliam na compreensão das decisões que os atores políticos tomam ao longo de suas carreiras (SCHLESINGER, 1966), buscou-se conhecer os elementos que exercem influxo sobre o modo de agir e as estratégias adotadas para a satisfação de suas ambições. No entanto, algumas questões, como o peso da associação com o chefe do 
Executivo no resultado das eleições e, por via reflexa, na eficácia das instituições parlamentares responsáveis pela accountability horizontal, ainda carecem de análises.

O presente trabalho busca, neste sentido, oferecer uma reflexão sobre o papel desempenhado pelos partidos políticos na forma como atuam os deputados federais na arena legislativa. Neste sentido, serão exploradas as seguintes questões: A atuação dos congressistas ocorre de forma individualizada ou os partidos políticos condicionam ou auxiliam a entender o comportamento dos deputados na arena legislativa? Pode se dizer que a atuação dos parlamentares orientada a políticas distributivistas ou programáticoideológicas pode ser conhecida pelo posicionamento ideológico dos partidos?

\section{MODALIDADES E CONDICIONANTES DAS ATIVIDADES PARLAMENTARES}

Nesta seção, a partir de uma revisão da literatura que aborda o tema, pretende-se, muito embora não seja possível esgotar a questão proposta, apontar argumentos e ideias que contribuam para avançar na compreensão do comportamento político dos membros da Câmara dos Deputados, indicando uma possível futura agenda de pesquisa.

Antes de abordarmos especificamente o tema deste trabalho, é importante destacar que a atuação dos parlamentares brasileiros encontra-se limitada a certos fatores, de natureza exógena e endógena (PEREIRA \& RENNO, 2007). Sobre os fatores de natureza exógena, ressalta-se que o poder Executivo possui forte influência na definição da agenda e dos trabalhos parlamentares. Com efeito, a partir da leitura do texto constitucional, pode-se observar que o presidente da República reúne consideráveis poderes de iniciativa e de decreto (SHUGART \& CAREY, 1992) os quais viabilizam potencialmente a sua interferência na atividade das Casas Legislativas.

Especialmente no que tange à participação do presidente da República no processo de produzir leis e demais atos normativos, observa-se "[...] que o deslocamento da iniciativa legal do Poder Legislativo para o Executivo é uma realidade que se consolidou aos poucos ao longo do século 20" em diversos países (PESSANHA, 2002, p. 180), oriundos de diferentes regiões do globo e ancorados em tradições histórico-políticas 
diversas, como ressaltado no Coalitional Presidentialism Project, recente estudo publicado pela Oxford University ${ }^{1}$.

O protagonismo do presidente da República na atividade de produção de leis mostra-se presente no sistema político brasileiro, sobretudo em virtude de fatores endógenos ao Poder Legislativo, relacionados "[...] à estrutura interna de alocação de poderes no legislativo. A Câmara dos Deputados possui um alto grau de centralização em sua organização interna e seu processo decisório." (PEREIRA \& RENNO, 2007, p. 670), o que favorece a construção de alianças entre Executivo e Legislativo por intermédio dos partidos políticos.

Tem-se assim que "[...] o modo de operar do governo brasileiro é o mesmo da maioria das demais democracias contemporâneas. O Executivo controla a agenda legislativa, logrando aprovar a maioria de suas proposições porque ancorado por sólido e consistente apoio partidário" (LIMONGI, 2006, p. 20). O chefe do Executivo brasileiro, então, pode ser visto como agente que desempenha papel de acentuada relevância no processo de tomada de decisões políticas, privilegiado por um sistema jurídicoinstitucional que o municiou com amplos poderes que o permitem atrair apoio dos membros do Legislativo e conferir estabilidade e racionalidade à atividade legiferante.

Desse modo, admite-se razoável supor que, tendo em vista o "[...] quadro de baixos incentivos e fortes restrições para desenvolvimento de uma carreira política baseada em atividades legislativas em Brasília, os caminhos para o sucesso eleitoral apontam na direção do reduto eleitoral" (PEREIRA \& RENNO, 2007, p. 670).

Feitas estas breves considerações, necessárias para se compreender o contexto em que se opera a atividade parlamentar brasileira, é importante apontar como alguns autores buscam explicar a atuação dos congressistas na construção de uma home career

${ }^{1}$ De acordo com seus organizadores: "The Coalitional Presidentialism Project (CPP) is directed by Paul Chaisty, Nic Cheeseman and Timothy J. Power at the University of Oxford. The project is motivated by the surprising sustainability of multiparty presidentialism in Africa, Latin America, and postcommunist Europe. Despite predictions to the contrary, presidents have been remarkably successful at winning legislative support from fragmented legislatures. The project has two principal objectives: (1) to identify the tools that presidents use to govern in concert with multiparty legislatures and (2) to assess the effects of these tools on horizontal accountability in new democracies. To investigate these questions, the project conducts original comparative analysis of nine emerging democracies between 1979 and 2010 - in Africa (Benin, Kenya, Malawi), Latin America (Brazil, Chile, Ecuador), and the former Soviet Union (Armenia, Russia, Ukraine). The project will generate considerable new data and will integrate case-specific knowledge into a rigorous cross-regional framework. In 2013, the CPP project will hold three regional dissemination workshops in Brasília, Kyiv, and Nairobi, and in 2014 the project will conclude with a major international conference to be held at the University of Oxford. The project began on September 1, 2011 and will conclude on August 31, 2014" Mais informações sobre o projeto podem ser obtidas no endereço: http://users.ox.ac.uk/ latc0045/CPP/About_CPP.htm . 
(FENNO, 1977), ou, em outras palavras, como os congressistas buscam satisfazer os interesses de suas bases e, por conseguinte, se posicionar no mercado eleitoral.

São três as formas básicas, de acordo com Mayhew (2005), utilizadas pelos congressistas com o intuito de se reeleger: advertising, credit claiming e position taking. A primeira delas diz respeito à atividade de disseminar o seu nome perante o eleitorado, no sentido de criar uma imagem favorável a partir de comunicações e contatos com os eleitores, o que não costuma estar associado ao debate ou implementação de uma política específica.

Sobre o credit claiming, tem-se que o parlamentar atua reivindicando para si a responsabilidade por um benefício considerado importante pelos eleitores. A atuação correspondente ao credit claiming, em geral, produz benefícios particularizados para a base eleitoral (pork barrel) ou envolve a intermediação de demandas junto a órgãos e entidades da administração pública (casework).

Por sua vez, a terceira forma de atividades nas quais se envolvem os parlamentares, conforme Mayhew (2005), consiste na position taking. Através da tomada de posições, os membros do Legislativo se revelam favoráveis ou contrários a algumas questões que apresentem, ao menos potencialmente, efeitos eleitorais.

Em um cenário no qual não há considerável identificação partidária, nem tampouco incentivos institucionais para o fortalecimento dos partidos políticos no plano eleitoral, admite-se que os parlamentares, individualmente, buscam se afirmar no mercado eleitoral notadamente por meio de credit claiming e position taking, associadas, respectivamente, a políticas de cunho distributivista e programático-ideológica. Contudo, apresenta-se o argumento de que os partidos políticos atuam como condicionantes para explicar quais estratégias de atuação adotam os parlamentares na arena legislativa.

Dito de outra forma, os partidos políticos, apesar de não auxiliarem como rótulos seguros para se conhecer o comportamento eleitoral, condicionariam as possibilidades de atuação de seus membros, na medida em que seu posicionamento em relação ao partido que ocupa o governo federal (situação/oposição) pode thes oferecer vantagens e obstáculos capazes de influenciar na decisão sobre como seus membros buscarão se diferenciar no mercado eleitoral.

Dessa maneira, argumenta-se que os partidos políticos são considerados como agremiações de homens que lutam, de modo competitivo, pela conquista ou manutenção de poder político (SCHUMPETER, 1961). Sendo assim, os agentes políticos utilizam-se 
das estratégias disponíveis no plano institucional para reduzir o nível de incerteza no que tange à continuidade no exercício de mandatos.

Destaca-se que, após a imposição de limites à migração partidária no Brasil, parlamentares com interesse em dar continuidade às suas carreiras políticas foram estimulados a adotar uma nova estratégia. Percebeu-se que os recursos institucionais conferidos ao presidente pela constituição vigente e distribuídos aos seus aliados, então, serviriam como atrativos à participação de partidos em coalizões, notadamente ao se observar que a concessão de espaços no governo aos aliados tem se revelado estratégia comum na composição dos últimos gabinetes presidenciais (LAMEIRÃO, 2009).

O imperativo de sobrevivência política, associado a um cenário de considerável incerteza eleitoral, assim, serviria como fator condicionante do comportamento de um deputado que busca a manutenção de seu espaço na Casa Legislativa (MELO, 2003). Por conseguinte, a inserção de um partido político na base aliada assim como o surgimento de novos partidos para a reacomodação de elites - provável reflexo da maior centralização decisória destas agremiações, ocorrida após as reformas estatutárias realizadas nos últimos anos (RIBEIRO, 2013) - os quais, eventualmente, buscarão seu espaço no governo, representam o interesse de parlamentares ansiosos pela redução dos riscos de não se reelegerem.

Nesse ponto, vale trazer os achados de Carvalho (2003), que serão melhor detalhados nas linhas seguintes, para oferecer um contraponto à sua tese. De acordo com o autor, é possível afirmar que há diferentes padrões comportamentais de deputados, posicionados em dois grandes blocos: a esquerda, cujos deputados adotariam uma posição mais ideologicamente orientada e a centro-direita, com parlamentares estimulados a produzirem políticas distributivistas.

Afirma-se, nesse instante, que esta conclusão, apresentada por Carvalho (2003) em seu livro, merece ser considerada com algumas ressalvas. Especialmente tendo em vista que seu trabalho se desenvolve a partir de um corte transversal limitado no tempo, fica a dúvida se as estratégias observadas não seriam resultantes da posição que os partidos ocupavam naquele momento específico.

Argumenta-se que é possível que os partidos de esquerda, na oposição em relação ao chefe do Executivo federal no momento em que o autor escreveu sua tese, utilizavam as estratégias disponíveis naquele instante. Considera-se, no entanto, que é relevante investigar se os padrões de atuação apontados por Carvalho (2003) foram mantidos ou se, e em que medida, alteraram-se a partir do instante em que os partidos de 
esquerda puderam usufruir das possibilidades decorrentes de sua relação com o poder Executivo.

Como destaca Inácio (2011, p. 168-169)

Diversos analistas identificam os partidos legislativos como agentes relevantes e capazes de modelar as estratégias parlamentares dos representantes. Essa perspectiva tem como foco as condições institucionais da relação entre os Poderes Executivo e Legislativo e seus impactos no processo decisório. Uma vez que os presidentes, detentores de amplos poderes legislativos, saem das urnas sem maioria e o Parlamento dispõe de recursos para bloquear a aprovação da agenda presidencial, os partidos assumem uma posição estratégica no processamento dessas decisões legislativas. Nesse contexto, cresce a interdependência entre as decisões alocativas dos parlamentares e dos partidos quanto ao investimento, em termos de tempo, recursos e atenção, em determinadas atividades legislativas. Se, por um lado, as recompensas aos congressistas são afetadas pela posição relativamente constrangida do Legislativo no processo decisório, por outro, o Poder Executivo passa a representar um vetor de distribuição de recursos relevantes para o sucesso eleitoral.

Acredita-se, de acordo com Engstrom e Vanberg (2010), que a lógica que rege a distribuição de pork barrel é partidária, e não particularista. Em seu estudo, os autores enfatizam o papel das lideranças na conciliação entre os interesses particulares dos deputados e os interesses coletivos da organização partidária. Haveria, nessa ordem de ideias, uma maior facilidade em se adotar políticas distributivistas (pork barrel e casework) por parte de deputados cujos partidos fossem integrantes da coalizão de governo. Aos oposicionistas, a política particularista seria menos viável, considerando a centralidade do Executivo na alocação de recursos (PEREIRA \& RENNO, 2007), o que deslocaria sua estratégia para atividade mais voltadas à tomada de posições, associadas a estratégias programático-ideológicas.

A importância da clivagem governo/oposição, que confere uma perspectiva dinâmica sobre a forma como os partidos e seus membros definem suas estratégias, pode ser corroborada ao considerarmos que

A preponderância do padrão de votação concentrado-compartilhado no PT em contraste à prevalência do tipo fragmentado-dominante no PMDB e PFL se deve aos posicionamentos opostos destes partidos no eixo situação oposição. Enquanto PMDB e PFL se constituíram como partidos de orientação governista após a transição à democracia, o PT e todos os partidos de esquerda, com poucas exceções, atuaram na oposição ao governo federal ao longo de boa parte do recente período democrático. (BORGES, PAULA \& NÓBREGA, 2015, p. 10) 
Não se pretende ignorar que as organizações partidárias possuem caraterísticas próprias, provenientes de seus processos de recrutamento (MARENCO \& SERNA, 2007) e decorrentes inclusive do momento de sua formação (PANEBIANCO, 2005; SHEFTER, 1994), que serviriam como vetores para se compreender a atuação de seus membros. Almeja-se, de fato, refletir sobre a possibilidade de alteração de alguns padrões de comportamento dos parlamentares tendo em vista o posicionamento de seu partido no eixo situação-oposição em relação ao partido do chefe do Executivo.

Com efeito, o recente trabalho de Borges, Paula e Nóbrega (2015) apresenta dados correspondentes ao percentual de candidatos a deputado federal de votação fragmentada e dominante, por partido, entre os anos de 1998 e 2010, revelando que a prevalência desse tipo de votação é bastante sensível à medida em que os partidos políticos se movem no eixo situação/oposição.

Este achado é bastante interessante, pois permite a formulação de algumas questões e hipóteses no sentido de que fatores ideológico-programáticos podem não contribuir em larga medida para compreender como os eleitores escolhem seu voto para deputado federal, tendo em vista que o eleitorado parece ser mais receptivo à clivagem governo/oposição, por razões de ordem cognitiva e institucional. O objetivo desta reflexão é ressaltar a razoável possibilidade de que o posicionamento ideológico de um partido político não fornece uma explicação suficiente para identificar se a atuação de um parlamentar é orientada a políticas distributivistas ou programático-ideológicas.

Ainda de acordo com os autores, observa-se que os candidatos incumbentes que fazem parte da coalizão de governo formada pelo presidente da República possuem, de fato, vantagens competitivas, talvez porque a estratégia fragmentado-dominante, considerada a mais segura pela literatura, está associada a candidatos pertencentes a partidos que integram a coalizão, que vislumbram a possibilidade de usufruir de recursos institucionais proporcionados pelo relacionamento de seu partido com o da chefia do Executivo. "Estes resultados fazem sentido se pensarmos que os deputados federais contam com melhores oportunidades de acesso aos recursos controlados pelos ministérios através de atividades de pork e intermediação de demandas" (BORGES, PAULA \& NÓBREGA, 2015, p. 26).

Nesse instante é relevante destacar que a concessão de coalition goods aos aliados do governo faz parte do processo de construção e manutenção de suporte parlamentar ao Executivo na Câmara dos Deputados (RAILE, PEREIRA \& POWER, 2011), viabilizada por intermédio dos partidos políticos. Corroborando o que foi afirmado 
até agora, o trabalho de Zucco Jr (2011, p. 58) indica que "[...] a clivagem estratégica e não ideológica entre governo e oposição parece ter ocupado o papel predominante na estrutura das disputas políticas na Câmara dos Deputados".

Desse modo, "[...] a participação no governo configura uma estrutura de escolhas distinta para os legisladores no tocante às decisões sobre a alocação de seus recursos" (INÁCIO, 2011), o que sinaliza para a possibilidade de que o posicionamento estratégico dos partidos políticos em relação à sua participação na coalizão governista nacional auxilia no condicionamento das oportunidades consideradas viáveis pelos parlamentares.

Vale a pena, neste momento, destacar alguns estudos desenvolvidos sobre a atividade legislativa brasileira, que enfrentam questionamentos acerca do conteúdo das leis apresentadas e aprovadas no Congresso Nacional. A preocupação mais importante, compartilhada na maioria desses estudos é identificar se a atividade dos membros do Legislativo tem como escopo a concentração ou difusão de benefícios, ou seja, determinar a abrangência geográfico-eleitoral da atuação dos congressistas.

Ricci (2003), em seu trabalho, observou o conteúdo das leis apresentadas e aprovadas no Congresso Nacional e defendeu a necessidade de análises empíricas pautadas nas características do arranjo institucional brasileiro em contraposição ao trabalho realizado por muitos autores que simplesmente importavam o modelo americano de conexão eleitoral ${ }^{2}$ e desempenho legislativo para as instituições brasileiras. Segundo Ricci (2003), parte da literatura argumentou que a produção legislativa dos parlamentares brasileiros é individualizada e puramente orientada para a adoção de políticas com efeito apenas no reduto eleitoral do legislador. Contudo, a partir dos anos de 1990 alguns trabalhos começaram a evidenciar o papel dos partidos políticos, das lideranças e o das regras decisórias internas do Congresso Nacional como variáveis a serem levadas em conta no estudo do processo decisório que se desenvolve na arena legislativa.

Os achados de Ricci (2003) indicam que a tese da conexão eleitoral brasileira, manifestada na ideia de que o parlamentar procura garantir benefícios locais voltados ao seu reduto eleitoral, precisaria ser reformulada ${ }^{3}$, por perceber que as leis microssecionais

\footnotetext{
${ }^{2}$ Em análise acerca da atuação dos parlamentares norte-americanos, Mayhew (2005) verificou que os congressistas eram orientados pelo objetivo máximo da reeleição. Para isso, era utilizado o mandato parlamentar para distribuir benefícios territorialmente definidos em detrimento da formulação de políticas públicas de abrangência nacional. Segundo Mayhew (2005), os benefícios alocados pelos parlamentares eram direcionados diretamente para os seus distritos eleitorais. Essa teoria, que possui abrangência nas considerações do modelo distributivista de atuação parlamentar, foi chamada de Conexão Eleitoral, tendo em vista a própria relação que existe entre os representantes e o eleitorado.

${ }^{3}$ De acordo com o autor, dos 838 projetos de lei apresentados no período entre 1991 e 2001, 531 deles possuíam temas com conteúdo geral/secional de impacto amplo. Presentes na categoria geral/secional foi
} 
de impacto local ou individual não alcançaram nem $10 \%$ do total registrado no período analisado.

O autor afirma que "[...] torna-se muito difícil continuar a sustentar a imagem de um congressista envolvido na distribuição de benefícios locais, ou a ideia de que ele não se interessa por questões nacionais e/ou secionais" (RICCI, 2003, p. 710). Indica também que não existe uma correspondência entre políticas locais e distritos de baixa magnitude, apesar de admitir que isso pode ser atribuído aos custos da competição na arena eleitoral. Em outras palavras, mesmo nos distritos com magnitude baixa, onde os custos de informação não seriam tão elevados, os custos da competição não são eliminados, pois decorrem da presença de vários candidatos no mesmo distrito. Assim, os resultados sugerem que a atuação legislativa dos parlamentares se volta, principalmente, à elaboração de leis nacionais, ou seja, a grande parte das leis produzidas pelo congresso geram impacto em todos os grupos de indivíduos, municípios, unidades da federação e regiões do país, em detrimento às leis de alcance reduzido que compreendem somente uma pequena parcela de indivíduos, localidades e regiões.

Outro ponto que merece atenção na análise do tema é a avaliação de uma possível correspondência entre a origem eleitoral de um congressista e o tipo de comportamento que este adota, tendo em vista a sua percepção do que considera mais relevante para a garantia de sua reeleição.

Buscando examinar o tema, Carvalho (2003) aplicou survey a 280 deputados da legislatura 1999-2003, com o objetivo de conhecer a visão dos parlamentares sobre três conjuntos de temas: a) o funcionamento dos partidos políticos; b) a relação dos deputados com suas respectivas bases eleitorais; c) as estratégias de reeleição e aspectos diversos da atividade legislativa.

Na primeira seção de seu trabalho, o autor expõe evidências que apontam para a observação de que a maioria dos entrevistados negligencia o papel dos partidos como atores coletivos que serviriam de atalho informacional na sua relação com os eleitores e, por conseguinte, de uma inclinação em direção à ênfase em políticas particularistas.

Utilizando as palavras do autor, "[...] se nos ativéssemos somente à análise da atitude manifesta por parlamentares, o modelo distributivista se afiguraria como modelo com importante rendimento para captar não só a lógica dos incentivos eleitorais, como a realidade operacional de nosso Legislativo" (CARVALHO, 2003, p. 145). 
No entanto, já na segunda seção, é possível perceber, ao desagregar os dados por blocos partidários, que há distinções nos padrões comportamentais de deputados integrantes de partidos de esquerda, de um lado, e, de outro, de partidos de centro e centro-direita.

Conforme já se indicou acima, em relação aos parlamentares de partidos de esquerda, seria possível observar, de acordo com Carvalho (2003), uma maior valorização, por parte destes, das atividades relacionadas à produção legislativa e à tomada de posições, o que indicaria um menor grau de personalização dos mandatos e, por via reflexa, um comportamento mais partidariamente orientado. No que diz respeito ao comportamento dos deputados de centro e centro-direita, tem-se a situação inversa. Estes parlamentares tenderiam a demonstrar fortes incentivos para perseguirem políticas distributivistas.

$\mathrm{Na}$ terceira seção, o autor apresenta dados que indicam que a origem geográfica, independentemente do posicionamento ideológico do partido do deputado, auxiliaria a compreender a atividade representativa.

Em ambos os blocos ideológicos, deputados com votação dominante manifestam atitude em relação ao desempenho do mandato representativo com clara ênfase, embora com intensidade diversa nos dois casos, no paroquialismo legislativo e na maximização de políticas distributivistas (CARVALHO, 2003, p. 146).

Pode-se verificar, nessa ordem de ideias, que os partidos são vetores relevantes para se observar e compreender o comportamento dos deputados na arena legislativa, especialmente na definição de suas estratégias e ações utilizadas para aumentar as chances de continuidade das carreiras de seus membros. As organizações partidárias atuam, assim, como agentes que desestimulam o comportamento individualista do parlamentar, associadas aos constrangimentos institucionais presentes no sistema brasileiro, que fortalecem o protagonismo do poder Executivo na atividade legislativa (INÁCIO, 2011).

Neste momento, a partir da leitura dos textos mencionados, considera-se importante destacar, novamente, algumas questões, que merecem ser enfrentadas, pois não parecem estar satisfatoriamente resolvidas pela literatura, demandando respostas de uma futura agenda de pesquisa.

Sobre o texto de Ricci (2003), pode haver um equívoco em se considerar a produção legislativa como proxy para mensurar o volume de políticas distributivistas. 
Considerando a amplitude da influência do chefe do Executivo na atividade legislativa, assim como tendo em vista a forma como o orçamento é executado no Brasil (PEREIRA \& RENNO, 2007), o texto parece sobredimensionar as possibilidades legislativas dos deputados. De acordo com a classificação proposta por Mayhew (1974), acredita-se que é razoável supor que a apresentação de projetos de lei possa ser melhor compreendida como tomada de posição.

É relevante destacar que o protagonismo do presidente da República no processo legislativo, possível sobretudo em virtude de alianças construídas com o Legislativo a partir de bases partidárias e da centralização decisória na Câmara dos Deputados, que atribui papel significativo ao Colégio de Líderes e à Mesa, desestimula ou reduz a eficiência de tentativas isoladas de atuação parlamentar. Em outras palavras, os partidos são verdadeiros agentes coletivos no processo legislativo, responsáveis por conferir certa racionalidade à atividade legiferante.

\section{CONSIDERAÇÕES FINAIS}

Destarte, muito embora se concorde com a proposição segundo a qual o momento de surgimento dos partidos imprime características que estes carregam ao longo de sua trajetória (PANEBIANCO, 2005; SHEFTER, 1994), vale a pena considerar que as estratégias adotadas pelos deputados podem adquirir uma perspectiva mais dinâmica, relacionada às possibilidades decorrentes do posicionamento adotado pelo seu partido em relação ao chefe do Executivo. Desse modo, deputados de partidos de esquerda e centro-direita, menos ou mais orientados às políticas distributivistas, segundo Carvalho (2003), poderiam alterar, em parte, o que consideram como estratégia ótima para a renovação de seus mandatos, tendo em vista a maior ou menor possibilidade de utilização de recursos disponíveis a partir da interação de seus partidos com o que ocupa a chefia do Executivo.

Tem-se, por hipótese, que os deputados não hesitariam em adotar uma estratégia que pudesse reduzir as incertezas eleitorais, buscando ampliar territorialmente sua base e aprofundar sua dominância nas localidades que o apoiaram em disputas anteriores. Considerando que o tipo de votação fragmentado-dominante (AMES, 2001) tende a ser "[...] mais frequente entre candidatos de partidos de situação no plano federal e estadual." (BORGES, PAULA \& NÓBREGA, 2015, p. 2), justifica-se uma avaliação das estratégias 
dos deputados cujos partidos deixaram de ser adversários e integraram o rol de integrantes da coalizão. Antes acostumados à condição de oposição, almejavam se destacar no mercado eleitoral a partir da tomada de posição. Diante da possibilidade de adoção de uma estratégia mais segura, viabilizada pelo posicionamento estratégico de seus partidos, os padrões de comportamento permaneceram os mesmos ou se alteraram?

Destaca-se que é razoável se pensar que existe, por razões de mercado eleitoral, uma tendência "rumo ao centro" no sistema partidário brasileiro, o que corroboraria a ideia de que existe a possibilidade de partidos, posicionados tradicionalmente em polos ideológicos distantes, adotarem estratégias até certo ponto semelhantes, considerando que as eleições para o legislativo se dão em um contexto de preponderância do Executivo (BORGES, PAULA \& NÓBREGA, 2015).

Assim, o estímulo à produção de políticas locais ou nacionais pode sofrer alguma interferência do posicionamento de um partido em relação àquele que ocupa a presidência da República, sobretudo ao considerarmos que maiores recursos são possíveis aos aliados, que, racionalmente, poderiam utilizá-los para promover estratégias eleitorais mais seguras, como a fragmentada-dominante.

Deste modo, argumenta-se que seria de grande relevância a realização de um estudo longitudinal, que considerasse a alteração da chefia do Executivo assim como a formação e manutenção de novas coalizões, para nos permitir observar se as estratégias se mantiveram ou, em que medida, foram alteradas por deputados que pertencem a partidos integrantes da coalizão. Um exame dessa natureza imprimiria uma perspectiva dinâmica ao comportamento dos parlamentares, que poderia se alterar de acordo com o posicionamento de seu partido em relação ao que exerce a presidência da República. Aceitando a premissa de que os agentes políticos buscam se eleger ou manter seus mandatos, seria razoável esperar que eles não desprezassem a adoção de estratégias tidas como mais seguras para a continuidade de suas carreiras.

\section{REFERÊNCIAS}

ABRANCHES, Sergio. Presidencialismo de coalizão: o dilema institucional brasileiro. Dados: Revista de Ciências Sociais, Rio de Janeiro: IUPERJ, vol. 31, nº 1, pp. 3-55, 1988. 
ALDRICH, John. Why parties? The origins and transformations of party politics in America. Chicago: Chicago UniversityPress, 1995.

AMES, Barry. Institutions and politics in Brazil. Ann Arbor: University of Michigan Press, 2001.

ARNOLD, Douglas. The Logic of Congressional Presidents and Assemblies. New Haven: Yale University Press, 1990.

BORGES, André; PAULA, Carolina de; NÓBREGA, Adriano da. Eleições legislativas e geografia do voto em contexto de preponderância do Executivo. Revista de Sociologia Política, 2015.

CARVALHO, Nelson Rojas de. E no início eram as bases: geografia política do voto e comportamento legislativo no Brasil. Rio de Janeiro: Revan, 2003.

DAHL, Robert. Poliarquia: Participação e Oposição; prefácio Fernando Limongi; tradução Celso Mauro Paciornik. - I. ed. 1. reimpr. - São Paulo: Editora da Universidade de São Paulo, 2005.

DOWNS, Anthony. Uma teoria econômica da democracia. Tradução: Sandra Guardini Teixeira Vasconcelos. São Paulo: Editora da Universidade de São Paulo, 1999.

ENGSTROM, Erik J.; VANBERG, Georg. Assessing the allocation of pork: Evidence from congressional earmarks. American Politics Research 38.6 (2010): 959-985.

FENNO, Richard. Congressmen in Committees. Boston: Little Brown, 1973. . US House members in their constituencies: An exploration. American Political Science Review 71.03 (1977): 883-917.

FIGUEIREDO, Argelina e LIMONGI, Fernando. Executivo e Legislativo na nova ordem constitucional. São Paulo: Editora FGV, 1999.

INÁCIO, Magna. Engajamento parlamentar no Brasil. In: POWER, Timothy J; ZUCCO JR, Cesar (org.). 0 Congresso por ele mesmo: autopercepções da classe política brasileira. Belo Horizonte: Editora UFMG, 2011.

KUNICOVÁ, Jana; ROSE-ACKERMAN, Susan. Electoral Rules and Constitutional Structures as Constraints on Corruption. British Journal of Political Science, Cambridge, 35., 2005. Disponível em:

http://authors.library.caltech.edu/2088/1/KUNbjps05.pdf. Acesso em: 15 ago. 2014.

LAMEIRÃO, Camila Romero. Ministros da Nova República e dirigentes públicos do governo Lula da Silva. In: ENCONTRO ANUAL DA ANPOCS. 33., 2009, Caxambu. Anais eletrônicos. Disponível em:

http://www.anpocs.org/portal/index.php?option=com_docman\&task=doc_view\&gid=1961\& Itemid=229. Acesso: em 28 jun. 2015. 
LIMONGI, Fernando. Poder de agenda na democracia brasileira: desempenho do governo no presidencialismo pluripartidário. In: SOARES, G; RENNÓ, L. (Org.). Reforma Política Lições da História Recente. Rio de Janeiro: Editora FGV, 2006.

LINZ, Juan J. The perils of presidentialism. Journal of democracy (Winter, 1993): 51-69.

\section{MAINWARING, Scott. Rethinking Party Systems in the Third Wave of}

Democratization: The case of Brazil. Palo Alto: Stanford University Press, 1999.

MARENCO, André; SERNA, Miguel. (2007). Por que carreiras políticas na esquerda e na direita não são iguais? Recrutamento legislativo em Brasil, Chile e Uruguai. Revista Brasileira de Ciências Sociais 22 (64) 93-113.

MARSTEINTREDET, Leiv. Explaining variation of executive instability in presidential regimes: Presidential interruptions in Latin America. (March, 2014) International Political Science Review, volume 35, number 2. Los Angeles, Sage Publications, pp. 173-194.

MAYHEW, David. Congress: the electoral connection, 2nd ed. New Haven: Yale University Press, 2005.

MELO, Carlos Ranulfo Félix de. Migração partidária, estratégias de sobrevivência e governismo na Câmara dos Deputados. In: TAVARES, José A. (org.). O sistema partidário na consolidação da democracia brasileira. Brasília: Instituto Teotônio Vilela, 2003.

MELO, Marcus André; PEREIRA, Carlos. Making Brazil Work: checking the president in multiparty system. New York: Palgrave Macmillan, 2013.

PANEBIANCO, Angelo. Modelos de Partido: organização e poder nos partidos políticos. São Paulo: Martins Fontes, 2005.

PEREIRA, Carlos; RENNO, Lúcio. (2007). O que é que o reeleito tem? O retorno: o esboço de uma teoria da reeleição no Brasil Revista de Economia Política, vol. 27, ㄲo 4 (108): 664-683.

PESSANHA, Charles. O Poder Executivo e o processo legislativo nas Constituições Brasileiras. Teoria e prática. In: VIANNA, Luiz W. (org.). A democracia e os três poderes no Brasil. Belo Horizonte: Editora UFMG, Rio de Janeiro: FAPERJ, 2002.

RAILE, Eric D; PEREIRA, Carlos; POWER, Timothy. (2011). The Executive Toolbox: Building Legislative Support in a Multiparty Presidential Regime. Political Research Quarterly 64 (2), 323-334.

RENNÓ, Lucio. Críticas ao presidencialismo de coalizão no Brasil. In: AVRITZER, Leonardo; ANASTASIA, Fátima (org.). Reforma política no Brasil. Belo Horizonte: Editora UFMG, 2006.

RIBEIRO, Pedro Floriano. Organização e poder nos partidos brasileiros: uma análise dos estatutos. Revista Brasileira de Ciência Política, Brasília, n. 10, Apr. 2013. 
RICCI, Paolo. O conteúdo da produção legislativa brasileira: leis nacionais ou políticas paroquiais? Dados. 46.4 (2003): 699-734.

SAMUELS, David. Ambition, federalism, and legislative politics in Brazil. Cambridge: Cambridge University Press, 2003.

SANCHES FILHO, Alvino de Oliveira; CARVALHO, André Borges de. Padrões de carreira política e desempenho eleitoral dos deputados federais em um sistema Executive-centric. In: ENCONTRO DA ASSOCIAÇÃO BRASILEIRA DE CIÊNCIA POLÍTICA, 8., 2012, Gramado. Anais eletrônicos. Disponível em: http://www.cienciapolitica.org.br/wpcontent/uploads/2014/04/12_7_2012_11_1_25.pdf . Acesso em: 14 ago. 2014.

SANTOS, Wanderley Guilherme dos. Anatomia da Crise. São Paulo: Vértice, 1986

SCHLESINGER, Joseph. Ambition and Politics. Chicago: Rand McNally, 1966.

SCHUMPETER, Joseph Alois. Capitalismo, Socialismo e Democracia - traduzido por Ruy Jungmann. Rio de Janeiro: Editora Fundo de Cultura, 1961.

SHEFTER, Martin. Political parties and the state: the american historical experience. Princeton: Princeton University Press, 1994.

SHUGART, Matthew Soberg; CAREY, John M. Presidents and Assemblies:

Constitutional Design and Electorl Dynamics. Cambridge: Cambridge University Press, 1992.

ZUCCO JR, Cesar. Esquerda, direita e governo. In: POWER, Timothy J; ZUCCO JR, Cesar (org.). 0 Congresso por ele mesmo: autopercepções da classe política brasileira. Belo Horizonte: Editora UFMG, 2011.

\section{NOTAS}

TÍTULO DA OBRA

Reflexões sobre o papel dos partidos no sistema político brasileiro: atividade parlamentar em contexto de preponderância do executivo.

Vinícius Silva Alves

Doutor em Ciência Política pela Universidade de Brasília

vinicius.silvalves@gmail.com

Ohttp://orcid.org/0000-0001-7880-0022

Endereço de correspondência do principal autor

Não se aplica.

FINANCIAMENTO

Capes.

CONFLITO DE INTERESSES

Não se aplica.

\section{LICENÇA DE USO}

Os autores cedem à Em Tese os direitos exclusivos de primeira publicação, com o trabalho simultaneamente licenciado sob a Licença Creative Commons Attribution 4.0 Internacional (CC BY). Estra licença permite que terceiros remixem, adaptem e criem a partir do trabalho publicado, atribuindo o devido crédito de autoria e publicação inicial neste periódico. Os autores têm autorização para assumir contratos adicionais separadamente, para distribuição não exclusiva da versão do trabalho publicada neste periódico (ex.: publicar em repositório institucional, em site pessoal, 
publicar uma tradução, ou como capítulo de livro), com reconhecimento de autoria e publicação inicial neste periódico.

\section{PUBLISHER}

Universidade Federal de Santa Catarina. Programa de Pós-Graduação em Sociologia Política. Publicado no Portal de Periódicos UFSC. As ideias expressadas neste artigo são de responsabilidade de seus autores, não representando, necessariamente, a opinião dos editores ou da universidade.

\section{HISTÓRICO}

Recebido em: 12 de março de 2017

Aprovado em: 03 de janeiro de 2019 